\title{
Los movimientos sociales de mujeres y su consolidación como interlocutor y actor político en la construcción de la paz en Medellín, Colombia*
}

\section{Women's social movements and their consolidation as interlocutors and political actors in the construction of peace in Medellín, Colombia*}

\author{
Javier Juárez Rodríguez ${ }^{* *}$ \\ Néstor Julián Restrepo Echavarría ${ }^{* *}$ \\ Nora Elena Botero Escobar ${ }^{* * * *}$
}

\begin{abstract}
Resumen: El artículo analiza el papel que juegan los movimientos sociales de mujeres en la exigencia de justicia dentro del conflicto colombiano, situándolas como actores reconocidos en el escenario político por la defensa de los derechos humanos y foco de contrapoder. Aplicando una perspectiva de género, se estudiaron las estrategias comunicativas que les han otorgado legitimidad a dos asociaciones, a saber: "Madres de la Candelaria" y "Mujeres Caminando por la Verdad", ambas situadas en Medellín, Colombia.
\end{abstract}

Palabras clave: Acción colectiva, actoras políticos, movimientos sociales, Derechos Humanos, estrategias de comunicación, conflicto armado.

\begin{abstract}
The article analyzes the role played by women's social movements in the demand for justice within the Colombian conflict, placing them as recognized actors in the political arena for the defense of human rights, as well as a focus of counter-power. Applying a gender perspective, we studied the communicative strategies that have given legitimacy to two associations, namely: "Mothers of Candelaria" and "Women Walking for Truth", both located in Medellín, Colombia.
\end{abstract}

Keywords: Collective action, political actors, social movements, Human Rights, communication strategies, armed conflict.

Recibido: 24 enero 2017

Aceptado: 28 marzo 2017

\footnotetext{
* Fuente de Financiación: Universidad de Medellín- Colombia. Filiación: Trabajo enmarcado en los Proyectos "Comunicación y Género" y "Movimientos Sociales de Mujeres en Antioquia" desarrollados dentro del Grupo de Investigación GRECO de la Facultad de Comunicación de la Universidad de Medellín (Colombia)

** Español, coautor, Doctor en Periodismo por la Universidad Complutense de Madrid, Profesor Investigador Universidad de Medellín. jjuarez@udem.edu.co

*** Colombiano, coautor, Doctorando en Política comunicación y Cultura de Universidad Complutense de Madrid, Profesor Investigador Universidad de Medellín. njrestrepo@udem.edu.co

**** Colombiana, coautora, Magister en Comunicación de la Universidad Tecnológica de Pereira, Profesora Investigadora de la Universidad de Medellín. nebotero@udem.edu.co
} 


\section{Introducción}

Para analizar y entender la evolución y el papel de los movimientos sociales de mujeres en Medellín y su aporte en la construcción de la paz en Colombia a través de su consolidación como interlocutor político es necesario abordar en primer lugar la realidad social de Medellín y el proceso de violencia que ha vivido en las últimas décadas. La historia reciente de Medellín, la segunda ciudad en población de Colombia después de la capital, Bogotá, ha estado marcada por un fenómeno de violencia surgido desde varios frentes, principalmente la derivada del conflicto armado interno y la surgida como consecuencia de la consolidación de estructuras delincuenciales ligadas al narcotráfico, la cual ocupó un lugar predominante, sobre todo, en la década de los ochenta y los noventa. Ha sido precisamente este último factor, la violencia ligada y derivada de la lucha entre cárteles, su legado de muerte y su permeabilidad social y cultural, la que ha granjeado a la ciudad durante décadas una imagen estereotipada tanto nacional como internacionalmente, ligada a la violencia y el narcotráfico, algo contra lo que se lucha desde hace años para su erradicación definitiva. Gracias, sobre todo, al esfuerzo y las reivindicaciones promovidas por la sociedad civil, organizada a través de asociaciones y colectivos, Medellín ha conseguido avanzar paulatinamente en la superación de los imaginarios dominantes durante finales del siglo pasado para consolidarse como una urbe moderna, afianzada como un motor económico, social y político lleno de oportunidades. Esto ha ocasionado que las personas afectadas por el conflicto armado que aún enfrenta Colombia, vean en Medellín un lugar para asentarse y rehacer su vida "en paz". Como consecuencia de esta realidad, hoy las laderas de la ciudad se ven repletas de familias en busca de otras oportunidades huyendo de una violencia que el Estado no ha podido neutralizar.

Aunque pueda resultar paradójico, los movimientos sociales en Medellín surgen como resultado de la organización de la sociedad civil ante la necesidad de dar respuesta y materializar su disconformidad con lo establecido e impuesto por los actores que rigen el sistema social dominante, consolidándose de este modo, como señala Manuel Castells ${ }^{1}$, como fuentes de contrapoder por su capacidad de cuestionamiento público de las acciones y las decisiones de los actores dominantes. Aplicando un análisis con sensibilidad de género, podemos observar como las mujeres han sido históricamente las grandes obviadas de los ámbitos de poder en Colombia, pese a lo cual han sufrido en primera persona la vulneración de sus derechos por parte de los actores masculinos del conflicto. El uso y abuso de su cuerpo, empleado como arma de guerra y parte de un lenguaje y un pacto específico entre hombres $^{2}$ ha sido una constante, ligada, además a una total impunidad y un preocupante silencio buscando la invisibilización.

Ante esta realidad se estructuraron los primeros movimientos de mujeres, que, a través de diferentes estrategias de comunicación empíricas, lucharon para cambiar tanto su realidad como la de su entorno. Por todo ello, la presente investigación aborda como

\footnotetext{
${ }^{1}$ Castells, Manuel, Comunicación y poder, Madrid, Alianza Editorial, 2009

${ }^{2}$ Segato, Rita Laura. Territorio, soberanía y crímenes de segundo Estado: la escritura en el cuerpo de las mujeres asesinadas en Ciudad Juárez. Brasilia. Departamento de Antropología Universidad de Brasilia. 2004. P. 11
} 
asunto metodológico el análisis de dos asociaciones que tienen su centro de operación en Medellín, y que a lo largo de los años se han consolidado como referentes reconocidos por la sociedad y los medios de comunicación, respetados por las características de su labor social, cuyas acciones han conseguido influencia y repercusión tanto nacional como internacional. Estos colectivos son "Madres de la Candelaria, Caminos de Esperanza" y "Mujeres Caminando por la Verdad"; ambos han focalizado su accionar en la atención de mujeres víctimas de la violencia en Colombia y se han consolidado como referente en el ámbito social que "desarrollando acciones colectivas defiende una causa o procuran una reivindicación de sus intereses" 3

El movimiento "Caminos de Esperanza Madres de la Candelaria" surge a finales de la década de los noventa, época especialmente violenta y convulsa, en la que se documentan continuas desapariciones forzadas ${ }^{4}$, secuestros, homicidios y masacres en todo el país. Por su parte, "Mujeres Caminando por la Verdad" surge en el año 2002 como respuesta, principalmente, a la Operación Orión, ejecutada en la Comuna 13 de Medellín, y los crímenes de perpetrados antes, durante y después de este operativo llevado a cabo en octubre de 2002.

Así pues, partimos de caracterizar un movimiento social como "aquel por el cual una categoría social, siempre particular, pone en cuestión una forma de dominación social (...) e invoca contra ella valores, orientaciones generales de la sociedad que comparte con su adversario para privarlo de tal legitimidad"5 En este sentido, analizamos la consolidación de estos dos movimientos como respuesta a la inacción y la ineficacia de los actores que ostentan el poder, que se ve firmemente determinado por la acción o la inacción, de estos actores y sus decisiones, obteniendo una contestación en forma "de acción política colectiva que implica la preexistencia de un conflicto que trata de resolverse a través de la movilización" 6 . Por todo ello, estos movimientos sociales se fortalecieron a través de personas convencidas de que los actores que ostentan y conforman el poder no han abordado correctamente sus preocupaciones ni respondido eficientemente a sus necesidades, consolidando una situación de deslegitimación ${ }^{7}$.

Para desarrollar un análisis preciso y completo sobre el papel de estas dos organizaciones en Medellín fue imprescindible entender que los movimientos de mujeres son la materialización de una respuesta de insumisión, un acto de sublevación contra el orden establecido por los actores que controlan y perpetúan el patriarcado. Como señala la investigadora Celia Amorós, el patriarcado implica la existencia de "pactos entre hombres"

\footnotetext{
3 Agudelo, Carlos, Nuevos actores sociales y relegitimación del Estado. Estado y construcción del movimiento social de las comunidades negras en Colombia, En Revista Análisis Político (Bogotá) n 43, mayo-agosto de 2001, p. 3

${ }^{4}$ Entendida como la privación de la libertad de una persona cualquiera que fuera su forma, cometida por agentes del Estado o por personas o grupos de personas que actúan con la autorización, el apoyo o la equidiscencia del Estado. Definición de la Convención Interamericana sobre Desaparición Forzada de Personas celebrada en 1993.

${ }^{5}$ Touraine, Alain, ¿Podemos vivir juntos?, Bogotá, Fondo de Cultura Económica, 2000, p.99

6 Martí i Piug, Salvador, “Los movimientos sociales en un mundo Globalizado: ¿alguna novedad?”, 2004, En: https://campus.usal.es/ dpublico/areacp/materiales/Losmovimientossociales.pdf

7 Castells, 2009, Op., Cit.
} 
que deben ser englobados dentro de "una especie de pacto interclasista" 8 . Ante esta dominación las mujeres se unieron para construir un potente movimiento de sororidad, entendido, según la antropóloga Marcela Lagarde, como "una solidaridad específica, la que se da entre las mujeres, que por encima de sus diferencias y antagonismos se deciden por desterrar la misoginia y sumar esfuerzos, voluntades y capacidades, y pactan asociarse para potenciar su poderío y eliminar el patriarcalismo de sus vidas y del mundo" 9 .

Por lo anterior en esta investigación toma cómo pregunta de partida:

¿Cómo las estrategias de comunicación de los colectivos de mujeres en Medellín les han permitido consolidarse como agentes de contrapoder e interlocutores políticos?

A partir de ella plantea como objetivo analizar los movimientos de sororidad que se gestaron a partir de las mencionadas asociaciones, que centraron sus reivindicaciones alrededor de la paz, la justicia y los derechos humanos y su consolidación como interlocutores sociales y actores políticos. Para ello, partimos de una hipótesis inicial fundamentada en que las mujeres han construido durante años de forma conscientemente los modelos y roles de género para dar significado a su activismo político. De esta manera, se puede decir que las mujeres mismas ven su activismo político como respuesta a un patriarcado hegemónico que históricamente ha tratado de silenciarles.

\section{Marco teórico y contextualización}

\section{Un contexto nacional marcado por la violencia}

Para entender la aparición y las dinámicas de acciones conjuntas de Asociaciones de Mujeres en Medellín es necesario conocer y analizar el contexto de la violencia documentado históricamente en Colombia, especialmente agudizado en esta ciudad, convirtiéndose estas mujeres en un foco de contrapoder tras ser víctimas directas del conflicto armando y las luchas urbanas.

Desde mediados del siglo pasado, el contexto social colombiano ha estado marcado por las dinámicas impuestas y normalizadas por los actores masculinos hegemónicos y protagónicos en el marco del conflicto armado: los problemas en materia de seguridad, la crisis humanitaria, que se agrava y se profundiza generando condiciones de vulnerabilidad para los sectores y grupos más desprotegidos de la sociedad, y la violación permanente de derechos fundamentales. Estas manifestaciones de violencia derivadas del conflicto han conducido a problemas como el desplazamiento forzado, la desaparición sistemática de personas y las masacres selectivas ${ }^{10}$, flagelos que se presentan agravados por la escasa o inapropiada respuesta por parte del aparato estatal.

\footnotetext{
${ }^{8}$ Amorós, Celia, Feminismo: Igualdad y Diferencia, México, PUEG- Programa Universitario de Estudios de Género, Universidad Nacional Autónoma de México. 1994, p.27

${ }^{9}$ Lagarde, Marcela, El feminismo en mi vida: hitos, claves y topias, México, Inmujeres, 2012, p. 34

10 Amnistía Internacional. Colombia: restituir la tierra, asegurar la paz. Los derechos territoriales de las comunidades indígenas y afrodescendientes. Reino Unido. 2015.
} 
Al analizar las causas de este proceso violento de desarrollo social, se encuentra entre sus principales factores la endeble institucionalidad del Estado, la brecha social consolidada como consecuencia de cambios socioeconómicos acelerados y una baja institucionalidad del poder público; la ruptura entre el Estado y la sociedad civil, la condición de pobreza y desigualdad de los ciudadanos, la lucha por el territorio por parte de diferentes actores reales que ostentan el poder, como son los grupos paramilitares, las guerrillas, y los grupos de narcotraficantes. A esta realidad, debemos sumar la brecha de género que históricamente ha predominado en una cultura como la colombiana en la que "ser mujer es un factor que suscita discriminación, y que, unido al estado de salud, a la edad, a la procedencia religiosa, étnica, cultural y socioeconómica, integra una matriz de factores que sustentan la marginación y la opresión."

\section{Antecedentes del Conflicto Político y Urbano en Colombia}

Pese al momento histórico que atraviesa actualmente Colombia como consecuencia del Proceso de Paz impulsado por el Gobierno de Juan Manuel Santos y las FARC-EP, el país no ha podido superar aún la situación de inseguridad, crisis y violencia estructural que viene arrastrando desde hace décadas. La raíz de este problema radica en parte en que desde los orígenes de la violencia política se pensó en el uso de la fuerza como única solución, enfrentando al Estado con los focos de resistencia armada, considerando que éstos serían reducidos fácil y rápidamente.

Para William Ortiz ${ }^{12}$ la aplicación de estas soluciones ha sido equivocada y más que ayudar, ha agravado la situación, pues un problema que estaba claramente localizado en sus inicios, con la intervención violenta de la fuerza pública se propagó por todo el territorio. De igual forma María Teresa Uribe ${ }^{13}$ plantea el ejemplo de la propuesta paramilitar que significó el paso de la seguridad ciudadana, bien público por excelencia y fundamento ético del Estado de derecho, al control privado, y la renuncia, por parte del Estado, al monopolio de la fuerza legítima, no porque un contrapoder se lo arrebatase en el escenario de la guerra abierta, sino por la cesión gratuita de este monopolio a un paraestado, cuyos mecanismos de control se escaparon a las posibilidades de un gobierno débil y que "se fortalece básicamente cuando hay una emancipación paulatina de las fuerzas armadas, la desconexión y la confrontación con el poder civil". ${ }^{14}$

\section{Medellín, paradigma de la violencia}

En el caso de la ciudad de Medellín han sido varios los diagnósticos e investigaciones académicas que centraron su atención en el aumento de muertes violentas o el auge de

\footnotetext{
${ }^{11}$ Hernández, Colombia y Yepes, Fanny Lucia, Haciendo visible lo invisible. Violencia de género y entre generaciones en una comunidad indígena colombiana, En Revista Investigación y Educación en Enfermería, Universidad de Antioquia, Vol 28, n 3 (Medellín), p.449

${ }^{12}$ Ortiz, William, Los paraestados en Colombia, Tesis Doctoral, Facultad de Sociología y Ciencias Políticas, Universidad de Granada (España), 2006.

${ }^{13}$ Idem.

${ }^{14}$ Ortiz, 2006, p.96., Op., Cit.
} 
grupos delincuenciales como los causantes del conflicto armado en la ciudad. Para autores como Ralph Rozema ${ }^{15}$ este aumento exponencial de la violencia en la ciudad se empieza a estudiar desde la óptica de los nuevos conflictos urbanos, donde la lucha y el control por el espacio público se solapan con el abandono del Estado y sus instituciones. La violencia urbana en Colombia se distingue por la presencia de una gran variedad de grupos armados: delincuenciales, paramilitares, guerrilleros y narcotraficantes que establecieron su poder en los barrios o comunas de las grandes ciudades del país y especialmente de Medellín, donde zonas como la Comuna 13 pasaron a ser espacios altamente peligrosos y en permanente disputa por estos actores ${ }^{16}$.

El fenómeno de violencia en Medellín se puede analizar a través de tres grandes momentos según los estudios de Ortiz y Rezema ${ }^{17}$ : el primero, se caracteriza por establecer la relación de la casualidad entre el carácter acelerado del crecimiento urbano, la pobreza y la violencia narcotraficante que se enmarco desde principios de los años ochenta; en un segundo momento, que abarcó toda la década de los noventa, el conflicto estuvo centrado en la cultura y el comportamiento violento, debido a la extensión y prolongación del conflicto y la descentralización administrativa del poder político en Colombia, que ayudó a consolidar los grupos armados en los territorios donde el Estado no llegó, además de la guerra sin cuartel que se libró en las calles de Medellín entre los carteles de la droga y el Estado. Por último, en una tercera fase, se produce el escalamiento del conflicto colombiano en la ciudad, donde los grupos de paramilitares y guerrillas entran en su accionar en las ciudades, disputándose el control micro tráfico y de los combos delincuenciales.

\section{Un análisis con sensibilidad de género}

Lo anterior muestra claramente como la población civil fue cada vez más víctima del conflicto, no solo por estar atrapada entre dos fuegos, sino porque durante toda la historia del país ha sido directamente blanco de los ataques, afectando sobre todo a la población más vulnerable. Es aquí donde debemos, nuevamente, aplicar una perspectiva de género para evidenciar que las mujeres han sido a lo largo de las últimas décadas víctimas silenciadas. En este sentido la investigadora Paula Guisao ${ }^{18}$ denuncia que la violencia sexual contra niñas y mujeres ha sido una práctica generalizada en el conflicto armado colombiano empleada por guerrilleros, paramilitar y miembros del Ejército.

De igual forma, organizaciones internacionales, como Amnistía Internacional en sus informes "Eso es lo que nosotras exigimos. Que se haga justicia: Impunidad por actos de

\footnotetext{
${ }^{15}$ Rozema, Ralph, Paramilitares y Violencia Urbana en Medellín, Colombia, En Foro Internacional, Vol. XLVII, n. 3 Julio- Septiembre de 2007, México, p. 535

${ }^{16}$ Aricapa, Ricardo, Comuna 1, crónica de una guerra. De Orión a la Escombrera, Bogotá, Ediciones B, 2015.

${ }^{17}$ Ibid.

${ }^{18}$ Guisao, Paula, De mujeres, luchas y memorias en el conflicto colombiano, Buenos Aires, En Memorias del IV Seminario Internacional de la Memoria, 2011.
} 
violencia sexual cometidos contra mujeres en el conflicto armado de Colombia" ${ }^{19}$ o "Déjennos en Paz: la Población civil víctima del conflicto armado interno de Colombia"20 advierten que el conflicto afecta sobre todo a las comunidades de mayor riesgo, cuyas voces apenas se escuchan, como son las mujeres, afrodescendientes, mujeres indígenas, campesinas y pobladoras de barrios de las periferias de las ciudades, muchas de ellas ya desplazadas.

\section{Los movimientos de mujeres en Colombia y Medellín}

Aunque los primeros movimientos de mujeres en Colombia datan desde hace casi un siglo con la aparición de colectivos sufragistas de mujeres ${ }^{21}$, no es hasta la segunda mitad del siglo XX cuando se visibiliza y organizan acciones y reivindicaciones conjuntas y efectivas. Estos colectivos serán identificados en un primer momento con corrientes o partidos políticos de izquierdas, así como movimientos sindicales o universitarios, e irán multiplicándose por toda la geografía nacional "en momentos de fuertes restricciones a la movilización y represión a las expresiones que fueran o parecieran subversivas" $" 22$.

La década de los noventa consolida una nueva realidad en los ámbitos asociativos y reivindicativos con la formación de colectivos impulsados, básicamente, por madres, hijas o hermanas de personas víctimas directas o indirectas del conflicto armado colombiano. Las mujeres son "obligadas" a ser activistas ante un Estado ausente, y unirán sus fuerzas y objetivos no ya solo en la reivindicación de derechos para las mujeres, sino en la construcción de una nueva Colombia desde la justicia, la memoria y la reconciliación con una participación femenina activa. De este modo, tomarán fuerza los movimientos impulsados y liderados por mujeres pero con una nueva finalidad: el empoderamiento de estas mujeres, su visibilización y participación activa, la formación y, sobre todo, la solidaridad mutua entre ellas. Gran parte de los colectivos de mujeres representan lo que la investigadora Lola Luna denomina como "movimientos de madres contra la violencia" y "movimientos por la supervivencia",23

Está dinámica bélica de Colombia ha conllevado de una manera u otra la participación de las mujeres en la política, creando en el grupo de madres una necesidad de autorepresentación y defensa de sus vidas. En palabras de Ana Teresa Bernal ${ }^{24}$, Presidenta

\footnotetext{
${ }^{19}$ Amnistía Internacional, Eso es lo que nosotras exigimos. Qué se haga Justicia: Impunidad por actos de violencia sexual cometidos contra mujeres en el conflicto armado de Colombia, Madrid, EDAI, 2011

${ }^{20}$ Amnistía Internacional, Déjenos en Paz: la población civil víctima del conflicto armado interno de Colombia, Madrid, EDAI, 2008

${ }^{21}$ Luna, Lola, Los movimientos de mujeres en América Latina y la Renovación de la historia política. Centro de Estudios de Género, Mujer y Sociedad. Editores La manzana de la discordia. Facultad de Humanidades de la Universidad del Valle, Cali. (Colombia). 2003.

${ }^{22}$ Lamus, Doris, De la subversión a la inclusión: movimientos de mujeres de la segunda ola en Colombia 1975-2005. Instituto Colombiano de Antropología e Historia. Bogotá (Colombia). 2010. p. 111

${ }^{23}$ Luna, Lola, Los movimientos de mujeres en América Latina y la Renovación de la historia política. Centro de Estudios de Género, Mujer y Sociedad. Editores La manzana de la discordia. Facultad de Humanidades de la Universidad del Valle, Cali. (Colombia). 2003. p.75-76

${ }^{24}$ Bernal, Ana Teresa, Memorias del Foro Iniciativas de Paz: una lógica de vida, Mayo 24 de 2005, En: http://documentos.pas.org.co/Memorias_Foro\%20Iniciativas\%20de\%20Paz\%202005.pdf
} 
de Redepaz: "Las Madres son el resultado de la saturación del crimen. Cada día se han ido volviendo las madres de todos y han construido una forma de maternidad social, que han cambiado el cuidado de la casa, por el cuidado de la vida, sean protagonistas de la verdad y la justicia y nunca de la venganza”.

\section{Desarrollo}

\section{Hipótesis y objeto de la investigación}

La presente investigación parte de una hipótesis principal: La consolidación de Movimientos sociales de mujeres como interlocutores válidos y actores políticos reconocidos en la construcción de la paz en Medellín.

Junto a esta hipótesis de partida, abordamos, a su vez, el análisis de otras hipótesis secundarias que son desarrolladas a lo largo de la investigación, que son:

1. La importancia esencial de las estrategias comunicativas como bastión de las acciones y reivindicaciones de estos colectivos.

2. La existencia y el papel de la sororidad, entendida como una solidaridad específica entre mujeres, para superar la violencia y el dolor de forma colectiva y resiliente.

3. La consolidación de estos movimientos como fuente de contrapoder a través de sus acciones públicas.

Paralelamente, el objeto de estudio para la verificación de nuestra hipótesis se ha basado en un análisis de caso centrado en las acciones y estrategias comunicativas impulsadas por dos asociaciones medellinenses lideradas y conformadas por mujeres (Madres de la Candelaria y Mujeres Caminando por la Verdad) que a lo largo de los últimos años han alcanzado una destacable notoriedad y reconocimiento social.

\section{Objetivos y Metodología}

Este artículo analiza, a través del estudio de dos organizaciones concretas ya mencionadas, las estrategias de comunicación impulsadas para visibilizar lo invisible, es decir, los excesos y abusos de los actores del conflicto y muy especialmente, las perpetradas por el propio Estado. Se estudiarán las estrategias que han legitimado a estos movimientos como actores políticos en materia de la defensa de los derechos humanos. Como objetivos específicos, buscaremos dilucidar el rol que ha asumido este movimiento como referente institucional y la responsabilidad que asume en la participación política y las estrategias comunicativas desarrolladas para insertarse en la agenda pública de los derechos humanos.

Con el fin de abarcar la temática propuesta, la investigación se abordó desde una perspectiva cualitativa, donde la exploración de los hechos y la descripción de los mismos, 
marcaron el procedimiento metodológico ${ }^{25}$. Para estos fines nos centramos en la realización de un trabajo de etnografía, llevando a cabo observación participante y acompañando a ambos movimientos de mujeres en marchas, plantones y diferentes actividades donde ellas participaban. También, a modo de triangulación, utilizamos como instrumentos las entrevistas semiestructuradas e historias de vida. Recurrimos a esta metodología con el objeto de obtener testimonios y datos inéditos que agudizaran la calidad del trabajo y la exclusividad del mismo. De igual forma, esta labor metodológica nos ha servido para interactuar con personas y agentes que intervienen en el fenómeno, entre ellos periodistas y autoridades del ámbito local, pues como señalan Klaus B. Jensen y Nicholas W. Jankowski ${ }^{26}$ los hechos deben conceptualizarse como expresión de una subjetividad y como la representación de un contexto concreto en el que participan varios actores.

No obstante lo anterior, la observación participante activa y crítica que realizamos es una de las herramientas más importantes a lo largo de nuestro proceso investigativo, ya que permitió hacer comparaciones, verificaciones, precisiones y transformaciones de fondo en la concepción del proyecto y en las técnicas.

Por su parte, el proceso de análisis responde a una caracterización definida desde el marco teórico, donde las categorías principales abordadas fueron el activismo de liderado por mujeres, fundamentado en movimientos de sororidad, las estrategias de comunicación y relaciones públicas para su consolidación como agentes de contrapoder en un primer momento, y como interlocutor válido y actor político en la construcción de la paz en Colombia en segunda instancia.

Teniendo presente que con nuestra investigación estábamos explorando un fenómeno humano, cambiante y disperso, susceptible de lanzar conjeturas a priori, el rigor científico para el tratamiento de los datos recolectados estuvo enmarcado principalmente en criterios de credibilidad o también llamado de autenticidad ${ }^{27}$, toda vez que para nosotros era fundamental realizar una aproximación lo más cercana posible al fenómeno observado, fuimos cuidadosos y exigente a la hora de garantizar que los hallazgos fuesen extraídos de experiencias realmente vividas por las mujeres objeto de estudio, aquí la triangulación metodológica fue garante de este cometido.

\section{El Movimiento de Mujeres y sus Estrategias de Acción Colectiva en Medellín}

En las últimas décadas se ha observado que la participación política de la sociedad civil organizada ha tenido un impacto significativo en los ámbitos de la decisión pública y la adopción de políticas activas ${ }^{28}$. Para algunos autores, este fenómeno guarda estrecha

\footnotetext{
25 Baptista Lucio, Pilar; Hernández Sampieri, Roberto; Fernández Collado, Carlos, Metodología de la investigación. Tercera Edición. México. McGrawHill/Interamericana editores S.A. 2003.

${ }^{26}$ Jensen, Klaus y Jankowski, Nicholas, Metodologías cualitativas de investigación en comunicación de masas, Barcelona, Boch Casa Editorial S.A., 1993

27 Noreña, Ana Lucia; Alcaraz-Moreno, Noemi; Rojas, Juan Guillermo y Robellado-Malpica, Dinora, Aplicabilidad de los criterios de rigor y éticos en la investigación cualitativa, 2012, p. 267

${ }^{28}$ Solís, Juan Mario, Dos visione, dos historias de la Plaza de Mayo. Estrategias de Abuelas y Madres para la articulación de políticas públicas de la memoria en la Argentina, Seminario de Investigación, Salamanca, Instituto de Iberoamérica y Portugal, 2010.
} 
relación con la llamada democratización de los Estados, denominada por Samuel Huntington $^{29}$ como la tercera ola, donde se les atribuyen a estos organismos un papel destacado en el debilitamiento y la caída de los regímenes autoritarios.

En este espacio de confrontación política y social, las mujeres han sido participantes activas de los diferentes movimientos sociales, los mismos que han surgido a lo largo de estas últimas décadas. Algunos de estos tienen efectos a largo plazo y producen un cambio social significante; otros son pasajeros, pues se generan alrededor de un asunto inmediato y coyuntural, por lo tanto, una vez mueren se resuelve el problema. Sin embargo, coinciden en que la mayoría de los movimientos de mujeres intentan reformar algún aspecto de la sociedad, dejando de ser simplemente asociaciones aisladas, para transformarse en coaliciones de grupos alrededor del tema de la paz y los derechos humanos. Esta lucha con bases en movimientos feministas que han hecho frente no sólo a un problema puntual, "sino también a la dominación patriarcal" "30 que sistemáticamente les ha excluido de los ámbitos de decisión y poder, lo que provocó movimientos de sororidad exigiendo equidad y buscando la defensa de los derechos humanos. Esta organización colectiva les hará consolidarse como fuentes de contrainformación y referentes de contrapoder, entendido como parte de un "proceso de resistencia al poder, en nombre de intereses, valores y proyectos excluidos"31. Esos movimientos de mujeres serán, además, un dique contra la expansión del poder patriarcal que, como explica la investigadora Graciela Hierro, "se mantiene y perpetua por medio de violencia de género" y es apoyados por "todos aquellos que utilizan la violencia represiva" ${ }^{\$ 2}$ incluido el propio Estado. Sólo gracias a esta lucha liderada por mujeres, en Medellín se han conseguido avances en materia de justicia y equidad de género. Como ejemplo de lo anterior, en 2007 se crea en la ciudad la Secretaría de las Mujeres de Medellín con la que:

(...) la capital de Antioquia se convirtió en la primera ciudad colombiana, con una dependencia del más alto nivel administrativo exclusivamente responsable de contribuir a la igualdad de derechos y oportunidades entre mujeres y hombres, tendiente a eliminar las prácticas discriminatorias que por razones de género, obstruyen el desarrollo político, social, económico y cultural de las mujeres del municipio ${ }^{33}$.

\footnotetext{
${ }^{29}$ Huntington, Samuel, La tercera Ola: La democratización a finales del Siglo XX, España, 1994

${ }^{30}$ Lamus, Doris, La construcción de movimientos Latinoamericanos de mujeres/feministas: aportes a la discusión teórica y a la investigación empírica, desde la experiencia en Colombia, En Revista Reflexión Política, n.18, Bucaramanga, 2007, p.119

${ }^{31}$ Castells, 2009, , Op., Cit., p. 78

${ }^{32}$ Hierro, Graciela, Las mujeres asesinadas en Ciudad Juárez, En: Violencia Sexista. Algunas claves para la compresión del feminicidio en Ciudad Juárez, México, Programa Universitario de Estudios de Género, Universidad Nacional Autónoma de México, 2004, pp. 126-127

${ }_{33}$ Ariza, Gladys Rocio, Hacia la definición de la violencia en las relaciones de pareja como un problema de salud pública en Medellín a comienzos del siglo XXI, En: Revista del Centro de Estudios sobre la Mujer de la Universidad de Alicante, n 18, Alicante, p. 80
} 


\section{Los casos de "Madres de la Candelaria" y "Mujeres Caminando por la Verdad": Víctimas y actores políticos}

Para Colombia la década de lo noventa supuso una etapa convulsa marcada por la violencia rural y urbana, y las continuas desapariciones forzosas y secuestros. Es en este contexto en el que un grupo de mujeres de Medellín deciden reunirse con un mismo objetivo: solidarizarse en el dolor, humanizar a sus seres queridos desaparecidos y visibilizar una realidad escandalosa y opacada como es la desaparición forzosa de personas en Colombia. "La resistencia de las colombianas al conflicto hace hincapié en su fuerza moral, el respeto a la vida y los derechos humanos, tal es el caso de las "Madres de la Candelaria" - Línea Fundadora (...) el miércoles 17 de marzo de 1999 al medio día en el que fue su primer "plantón", que es como denominan los encuentros de cada ocho días frente a la Iglesia de la Candelaria de Medellín por estar plantadas. Esa vez cada familiar llevó consigo la foto de su ser querido desaparecido o secuestrado con la fecha del hecho y los autores" 34 .

El grupo se afianza como movimiento y fuente de contrapoder. Su persistencia, constancia y mensaje en pos de Paz y la Justicia obtiene reconocimiento social y el de los medios de comunicación que se hacen eco de sus mensajes. Cuatro años después de iniciar su lucha, nace la "Asociación Caminos de Esperanza - Madres de la Candelaria", el mismo que en la actualidad cuenta con alrededor de setecientas mujeres asociadas; compuesta principalmente por madres, hijas y hermanas de víctimas, sus historias registran casi mil casos de desapariciones forzadas y masacres. El grupo irrumpe y gana un espacio en la esfera pública a partir de su denuncia y la movilización, abanderando "los principios que orientan su lucha" como "son la insistencia, el amor, el respeto, el diálogo y la autonomía, apoyados en los valores del trabajo en equipo, el compromiso, el buen trato y la tolerancia (...) busca frenar la cadena de odio que alimenta el conflicto" 35 .

Por su parte, el grupo "Mujeres Caminando por la Verdad" se consolida en 2006 a través de movilizaciones como respuesta a los excesos del Gobierno de Álvaro Uribe a la hora de ejecutar la Operación Orión en la Comuna 13 de Medellín. Las mujeres fueron el bastión que, pasada más de una década, ha mantenido encendida la llama de la memoria en esta zona especialmente castigada por la violencia. Madres, hijas y hermanas de personas desaparecidas en la Comuna han luchado para frenar el olvido y exigir Justicia. La organización exigió durante años la búsqueda de restos en La Escombrera, en la Comuna $13^{36}$ una zona conocida como La Arenera, donde, según ex paramilitares desmovilizados, entre ellos el líder del Bloque Cacique Nutibara, Diego Fernando Murillo Bejarano "Don

\footnotetext{
${ }^{34}$ Martinez, Juliana, Las madres de la Candelaria- Línea Fundadora, En: Revista Anuario de Hojas Warmi, Universitat de Barcelona, n. 15, 2010, p. 3-4.

${ }^{35}$ Ibid., p.8

${ }^{36}$ RCN Radio, Mujeres caminando por la verdad en Medellín fue nominada a premio, 3 de Septiembre de 2015, En: http://www.rcnradio.com/locales/mujeres-caminando-por-la-verdad-de-medellin-fue-nominada-alpremio-nacional-a-la-defensa-de-los-derechos-humanos/ (Consultado el 2 de junio de 2016)
} 
Berna", habrían sido llevados, asesinados y enterrados decenas de víctimas de desaparición forzada antes durante y después de Orión.

La persistencia de estas mujeres en su lucha como respuesta al silencio gubernamental era reconocida en 2015 con el Premio Nacional a la Defensa de los Derechos Humanos, destacando su lucha incesante en la exigencia de Justicia. Su portavoz, Luz Elena Galeano, al recoger el Premio señalaba que su lucha había creado:

Huellas de resistencia por nuestros seres queridos (...) hemos ganado la palabra salido del silencio al que estábamos sometidas de la indolencia de una sociedad que nos invisibiliza y alzamos la voz por los derechos de todas las víctimas (..) seguimos exigiendo que el Estado reconozca su responsabilidad. La Escombrera es sólo un ejemplo de violación sistemática de los derechos humanos cuyos máximos responsables no han sido juzgados (...) Somos semilla, somos memoria, somos el sol que renace ante la impunidad $^{37}$

En la actualidad ambos movimientos son parte fundamental para la ejecución de las políticas públicas de derechos humanos en el departamento de Antioquia -Colombia-. Por su parte, las "Madres de la Candelaria" han apoyado a las instituciones públicas como la Fiscalía General de la Nación, la cual dentro de sus áreas tienen la Unidad de Justicia y Paz y la Unidad Integral de $N . N$ de Desaparecidos. Gracias al movimiento y a la información que ellas poseen, la Fiscalía ha conseguido hallar y exhumar cuerpos y darle viabilidad a las versiones libres de los paramilitares. Asimismo, "Mujeres Caminando por la Verdad" se han consolidado como el motor de la búsqueda de personas víctimas de desaparición forzada en la Comuna 13 de Medellín. Lo que ha dado sus frutos, pues desde julio de 2015 la Alcaldía de Medellín y la Fiscalía pusieron en marcha el proyecto 'Escarbando la verdad, desenterrando la Justicia' para tratar de localizar en la zona de La Arenera (Comuna 13) los restos de al menos 100 víctimas. Adicional a esto, gracias a la intervención de "Mujeres Caminando por la Verdad", la Alcaldía de Medellín creó la Unidad de Víctimas con el fín de hacer cumplir la política pública de atención y reparación de víctimas.

Como vemos, organizaciones sociales como las "Madres de la Candelaria" y "Mujeres Caminando por la Verdad", aparte de incidir en la agenda pública, han conseguido presionar en políticas públicas sobre derecho humanos gracias a la potenciación de ciertos atributos como: capital político, capital económico, capital organizacional y capital simbólico. Para Leiras ${ }^{38}$ el éxito de estas organizaciones civiles está condicionado por su capacidad de organización interna, la claridad y generalidad de sus reglas, la representatividad de sus miembros, la capacidad de movilización y por último, la capacidad de generar alianzas.

\footnotetext{
${ }^{37}$ Extracto del discurso de Luz Elena Galeano en el Centro Nacional de la Memoria y Reconciliación al recibir el reconocimiento el 9 de septiembre de 2015 en Bogotá.

${ }^{38}$ Leiras, Marcelo, La incidencia de las organizaciones de la sociedad civil en las políticas públicas. Definiciones, explicaciones y evaluaciones de la literatura especializada local e internacional, En: La incidencia política de la sociedad civil, Buenos Aires, Ed Siglo XXI, 2007.
} 
Concretamente, "Madres de la Candelaria", en su intervención en las políticas públicas, por un lado, han impulsado decididamente el desarrollo de los juicios contra los victimarios "paramilitares"; por el otro, han ayudado a organizaciones del Estado para conocer un listado serio y organizado de las víctimas del conflicto, lo que ha contribuido a un manejo más transparente de las indemnizaciones que por Ley de Justicia y Reparación deben ser entregadas a estas.

Ahora bien, el papel de las "Mujeres Caminando por la Verdad" no ha sido menor como actores políticos. Como señala el periodista Gustavo Ospina " "fue ese paso a paso el que fue forjando las bases del colectivo de mujeres que (...) se ha hecho visible por su lucha y fortaleza para no desistir en la esperanza de que el Estado tomara la decisión de buscar en La Escombrera los cadáveres de sus seres queridos asesinados y desaparecidos por los grupos en conflicto en la Comuna 13". El trabajo por la defensa de los Derechos Humanos, por la reconciliación y la paz, pasa por estos movimientos por la práctica más que por la formulación discursiva elaborada y académica. Las integrantes se involucran en el proceso de reconstrucción de la memoria social en pos de la sanación de las personas que han sufrido los hechos atroces. Esta es una tarea vinculada a la restauración del valor de la dignidad humana entre los ciudadanos y ciudadanas, más allá de las interpretaciones interesadas o partidistas, las disputas y divergencias que aparecen entre grupos sociales y entre individuos en relación a lo ocurrido ${ }^{40}$.

El las reivindicaciones de ambos grupos de presión la categoría social de víctima juega un papel central, pues de ella pende la visibilización de las experiencias violentas vividas por ellas, pero también se trata de una categoría que otorga sentido al pasado en su enlace con el presente. Esto porque el "sufrimiento provocado por la violencia política llevaría a quien lo vive a ocupar un lugar en la sociedad distinto al que ocupaba antes, contribuyendo a construir una identidad del sujeto acorde con ese lugar social" 41 .

\section{El papel de la comunicación en la visibilización de las mujeres en el conflicto colombiano: De los medios de comunicación a las relaciones públicas}

Tras años de luchas, ambas organizaciones se han consolidado como referentes informativos e interlocutores válidos para medios e instituciones públicas, rompiendo de este modo con el techo de cristal existente que fortaleció la hegemonía masculina-patriarcal "en donde el hombre representa lo público, la política, el dinero, las capacitaciones de negociación, la proveeduría, la sabiduría" ${ }^{42}$. Esta legitimación de su trabajo y sus reivindicaciones, vendrá respaldada por una estrategia de comunicación, que para un

\footnotetext{
${ }^{39}$ Ospina, Gustavo, Las mujeres que destaparon la verdad sobre La Escombrera, Periódico El Colombiano, En: http://www.elcolombiano.com/antioquia/excavacion-a-la-escombrera-una-lucha-de-un-colectivo-demujeres-IE2503864

${ }^{40}$ Citado por Antequera, José Dario, [Contribuciones para la reivindicación social de un derecho a la memoria] En Revista el Otro Derecho (Bogotá) n. 37, Bogotá, 2007, p. 71

${ }^{41}$ Truño, María, No solo víctimas: mujeres en el lugar social de víctima y relaciones de género, En: Revista el Otro Derecho (Bogotá) n. 36, Bogotá, 2007, p. 136

${ }^{42}$ Díaz, Flor, Estudio sobre la tolerancia social e institucional a la violencia basada en género en Colombia, Bogotá, UNIFEM, UNFPA, OIM Y MDGF, 2010, p. 45
} 
movimiento social implica un conjunto de procesos, procedimientos, acciones y recursos que se ponen en función de alcanzar unos objetivos y metas propuestas desde el punto de vista de la comunión. Para los movimientos el uso de las estrategias de comunicación aumenta las posibilidades de éxito de un determinado programa o proyecto en comparación con un movimiento que no aproveche adecuadamente la comunicación

Los movimientos sociales desarrollan esfuerzos estratégicos para dotar de sentido su movilización y exponer sus agravios tejiendo "redes activistas o redes de movimientos sociales" que generan "espacios comunicativos y de acción donde se comparten experiencias de lucha y de auto-organización", utilizando "siempre aquellos instrumentos comunicativos a su alcance para diseminar sus protestas" $"$. Para ello, la dependencia de los medios de difusión de masas sigue siendo clave, pues conforman la visión hegemónica del público sobre lo que sucede. En este sentido, ambas organizaciones diseñaron una efectiva estrategia de comunicativa basada en el análisis de la población y el contexto, con unos objetivos y unas metas claras y específicas: la difusión de Mensajes claro y el diseño de un plan de actividades ${ }^{44}$.

Tanto "Madres de la Candelaria" como "Mujeres Caminando por la Verdad" decidieron dejar de llorar en silencio por el dolor de sus desaparecidos para luchar, exigir respuestas y encontrar la verdad. Ellas han hecho de la comunicación el pilar de la denuncia y el bastión de sus reivindicaciones. Para ello, han consolidado a lo largo de los años su credibilidad como fuente de información de los periodistas y los medios de comunicación. Aunque en sus inicios ni ellas mismas eran conscientes de la importancia de las relaciones públicas para alcanzar sus objetivos, a lo largo de los años se han convertido en fuente de interlocución y actor válido en muy diversos sectores: las empresas, el Estado, las organizaciones armadas al margen de la ley, las ONG y personas influyentes para conseguir los objetivos trazados. Su labor comunicativa ha conseguido que sus reivindicaciones formen parte de la agenda pública y de los medios y han aportado una perspectiva de género en los hechos, lo que es "un pilar fundamental de las transformaciones sociales (...) que ha permitido cuestionar muchas actuaciones" 45 . Al mismo tiempo, han sabido adaptarse a las exigencias y los cambios que los medios han ido modulando, adecuando su estrategia informativa también a las redes sociales o páginas de internet para lograr que el mundo conozca su lucha. Sólo el trabajo de visibilización de estas mujeres ha conseguido situar a las mujeres, como género, en la categoría de actores válidos que deben ser escuchados. Sin embargo, "el abordaje de la perspectiva de género en relación con la comunicación es uno de los que presentan menor avance epistemológico (...) las asociaciones de mujeres se han mostrado pioneras en la integración de la comunicación en su gestión, así como en detectar su importancia" ${ }^{, 46}$.

\footnotetext{
${ }^{43}$ Rovira, Guiomar, Movimientos sociales y comunicación: la red como paradigma, En Revista Análisis (Bogotá) n.45, Bogotá, 2012, p. 92-96

${ }^{44}$ González, Eduardo y Varney, Howard, En busca de la Verdad. Elementos para la creación de una comisión de la verdad eficaz, Brasilia, González y Varney, 2013

${ }^{45}$ Benitez, Lucia, La perspectiva de Género en Comunicación al desarrollo, En Comunicación y Desarrollo: Prácticas comunicativas y empoderamiento, Barcelona, Gedisa S.A., 2015

${ }^{46}$ Ibid., pp. 217-220.
} 
En este sentido, "Mujeres Caminando Por la Verdad" ha logrado reconocimiento nacional e internacional, obteniendo, entre otros galardones, el Premio Nacional a la Defensa de los Derechos Humanos, en 2015. Luz Elena Galeano, portavoz de la organización y referente en la estrategia comunicativa de la asociación, señala que: En 2005 nace el Movimiento Nacional de Víctimas de Crímenes de Estado y se conforma "Mujeres Caminando por la Verdad" en 2008. Yo entro a formar parte de la asociación y a caminar por la resistencia, en movilizaciones (...) en nuestras campañas de comunicación hemos trabajado para sensibilizar a la sociedad civil y al Estado, porque el Estado ha sido negligente (...) la búsqueda de La Escombrera nos ha provocado emoción, pero también ansiedad. Hemos exigido a la Fiscalía que búsqueda sea integral, que no se busque solo en esta zona, y que se siga también en otros puntos de la ciudad (...) Esto es una gota de esperanza en un mar de impunidad. Son 13 años de resistencia y este paso es gracias a las conversaciones con la Fiscalía, con la Alcaldía de Medellín y organismos de derechos humanos que nos acompañan (...) Gracias a estas conversaciones llegamos a acuerdos y proceder a las excavaciones. $^{47}$

Como señala Luz Elena Galeano, Portavoz de Mujeres Caminando por la Verdad, las campañas y los mensajes de la organización han conseguido una notable repercusión internacional como consecuencia de su exigencia de Justicia en el esclarecimiento de las desapariciones forzadas de decenas de habitantes de la Comuna 13. "Mujeres Caminando por la Verdad" fue el motor de este búsqueda y, como señala Galeano, la muestra de que sólo desde la exigencia pública fue posible alcanzar la posición de interlocutor en el ámbito político y avanzar en la búsqueda de Justicia y esclarecimiento de los hechos, entendiendo la participación política como "aquel conjunto de actos y de actitudes dirigidos a influir de manera más o menos directa y más o menos legal sobre las decisiones de los detentadores del poder en el sistema político" (Bartolini, Cotta, Morlino y Pasquino, 1991:180) Esta consolidación de ambas organizaciones como actores activos de la participación política, rompía además, los prejuicios y las imposiciones de un sistema patriarcal que consideraba que la actividad política era de forma "natural masculina: Política= Espacio Masculino, y que potenciaba el alejamiento de las mujeres esfera pública y su reclusión en la esfera doméstica ${ }^{48}$.

\footnotetext{
${ }^{47}$ Galeano, Luz Elena, Entrevista personal de los autores realizada en septiembre de 2015

${ }^{48}$ Alcañiz, Mercedes, Aportaciones de las mujeres al discurso y a la práctica de la paz en Revista Feminismo/s, En Revista Feminismos (Alicante) n. 9, Alicante, 2007. pp. 31-50
} 
FOTOGRAFÍA No. 1 Luz Elena Galeano, portavoz de Mujeres Caminando por la Verdad colocando una foto de su marido, víctima de desaparición forzada en 2008. Fotografía tomada en Septiembre de 2015. Autor: Javier Juárez.

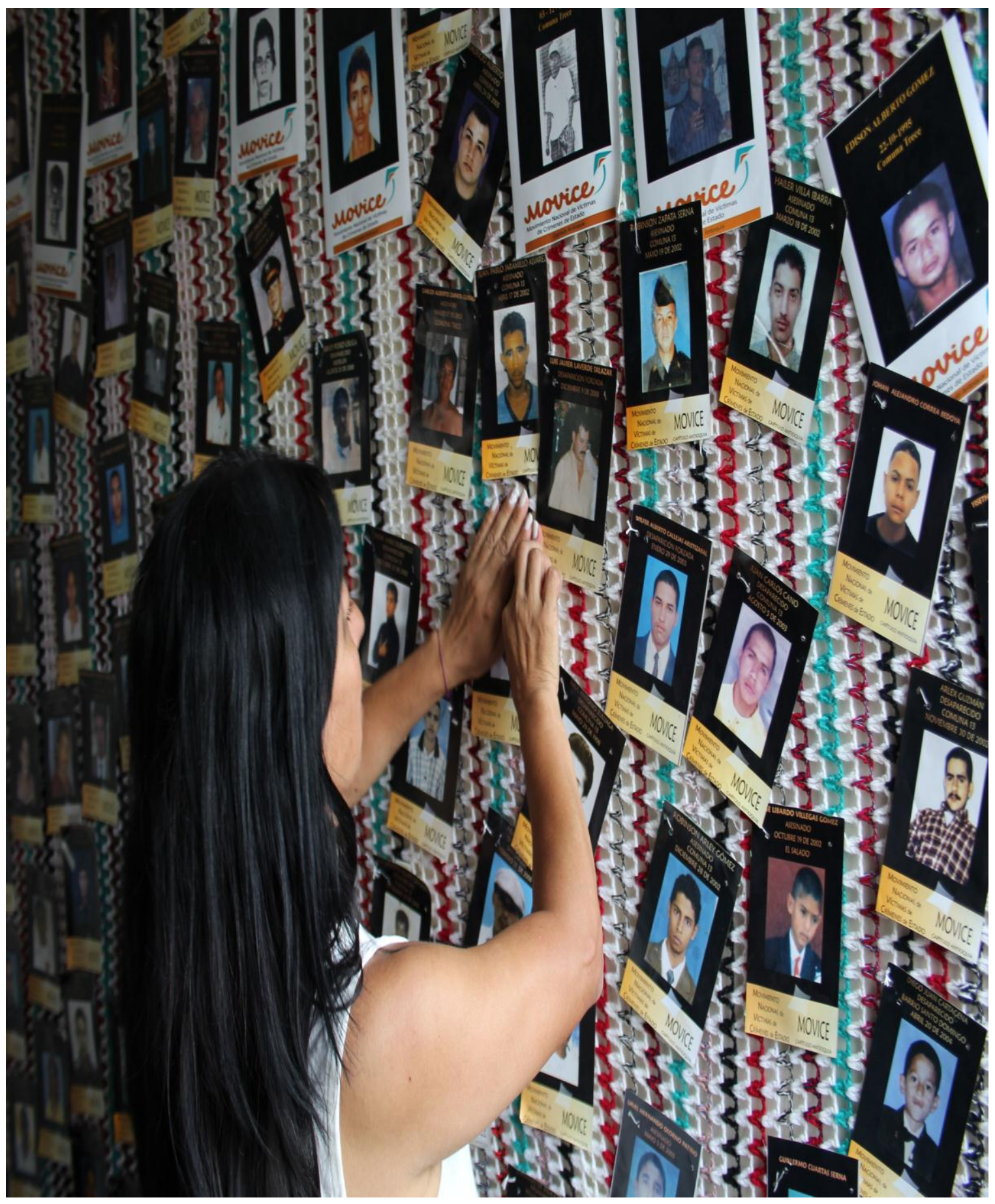




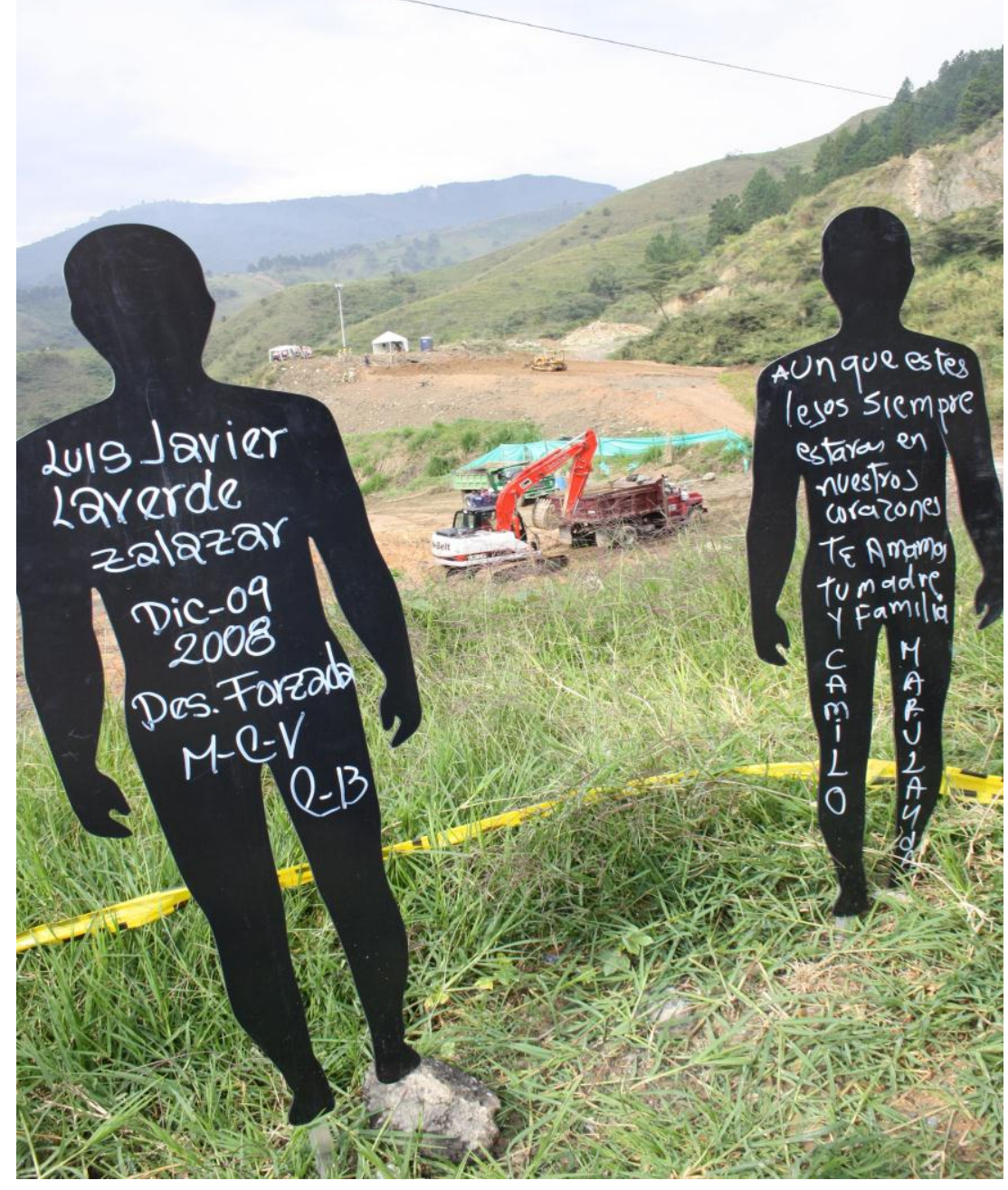

FOTOGRAFÍA No. 2 Búsqueda de cuerpos en la Escombrera en 2015. Fotografía tomada en septiembre de 2015 en el sector de La Arenera donde se procedió a buscar restos de desaparecidos de la Comuna 13 de Medellín. Autor: Javier Juárez

Centrándonos en el caso de "Madres de la Candelaria" podemos decir que la estrategia más importante, y la que ha dado mayores resultados, es sin duda la de El Plantón, el cual organizan cada viernes en la Iglesia de la Candelaria, situada en el Centro de Medellín, para mostrarle a la gente que su dolor es el dolor de todos los colombianos. Ellas, a través de los años, se han ganado ese espacio, convirtiéndose en el punto de encuentro de todos aquellos que tengan una historia similar, donde la memoria es una construcción conjunta que se manifiesta mediante lo simbólico: las imágenes, los cantos, las consignas, relatos, ritos públicos. El objetivo es la recuperación de la memoria además de elaborar un duelo en medio del conflicto. De igual forma El Plantón resignifica el rol maternal, trabajando en la reconstrucción de los imaginarios y los roles sexistas que relegaban a la mujer a un papel de sumisión reducido al ámbito doméstico. Ahora la mujer sale y ocupa intencionalmente los espacios públicos, reivindicando su papel de actor principal, ingresando en la esfera pública para demandar e interactuar con el Estado, la opinión pública y con los grupos armados, modificando, si se quiere, la noción clásica de madres/mujer, apropiándose de un discurso diferente a otros movimientos sociales.

En este sentido, hemos de destacar como ambas organizaciones han logrado una gran repercusión en los medios y un reconocimiento social con recursos muy limitados. La ausencia de profesionalización en materia comunicativa les hizo, incluso, ganarse más aún el respeto y el reconocimiento de periodistas y medios de comunicación, conscientes del 
esfuerzo de ambas organizaciones para conseguir trasladar a la sociedad sus reivindicaciones. En este sentido, el avance de las nuevas tecnologías en los últimos años también ha obligado a las organizaciones a adaptarse a estas realidades comunicativas, diseñando, no sin esfuerzo, canales digitales de comunicación como, por ejemplo, el blog digital, utilizado por ambas entidades ${ }^{49}$. Solo el esfuerzo y la persistencia de sus integrantes, unido a la ayuda externa de algunas voluntarias, han conseguido responder a las necesidades comunicativas y suplir las carencias existentes, así como la falta de medios y la no profesionalización de las estrategias comunicativas.

Han sido muchos los logros que en materia de comunicación y difusión han tenido estas organizaciones para alcanzar su objetivo. En una primera instancia, "Madres de la Candelaria" logra una vitrina para el movimiento que fue el premio Nacional de Paz en el año 2006, otorgado a la asociación en cabeza de su líder "Teresita Gaviria”. En este sentido, aunque ambas organizaciones proyectan una función de contrapoder respetado por el conjunto de la ciudadanía, también son reseñables las diferencias detectadas en el análisis de sus discursos. En este punto, es apreciable como mientras "Mujeres Caminando por la Verdad" aboga por un trabajo de permanente denuncia y exigencia de Justicia, señalando con nombres y apellidos a integrantes del Estado -cargos políticos de las Fuerzas de Seguridad- por su posible implicación y/o participación en hechos delictivos, "Las Madres der la Candelaria" abogan por una mensaje más tibio en este sentido y enfocado a la reconciliación. En este sentido, durante el transcurso de la presente investigación contamos con el testimonio de Teresa Gaviria, fundadora de "Madres de la Candelaria", quien señala que:

En nuestros deseos políticos, esperamos un gran robustecimiento de nuestra imagen, que nos fortalezca para plantear y exigir políticas en el tema de víctimas. Lo mismo que soñamos con el acceso permanente aun medio de comunicación donde nuestra voz de madres sea escuchada. Deseamos encontrarnos con nuestros victimarios para hablarnos y conocer la verdad. Y luego emprender con ellos el camino del perdón, el de los acuerdos restaurativos y la sostenibilidad de tal restauración. Nuestro mayor anhelo: sanarnos y sanar la memoria herida de este país. (Gaviria, Teresa. Entrevista realizada el 28 de agosto 2012 por Alba Shirley Tamayo Arango y Nestor Julián Restrepo para la presente investigación).

\footnotetext{
49 Madres de la Candelaria, En: http://redesmadresdelacande.wix.com/madresdelacandelaria Mujeres Caminando por la Verdad, En: http://mujereslaverdad.blogspot.com.co/
} 


\begin{abstract}
FOTOGRAFÍA No. 3 Plantón "Madres de la Candelaria". Cada viernes desde hace ya más de una década, las Madres de la Candelaria realizan su plantón para visibilizar su lucha. Autores: Javier Juárezl Nara E. Botero
\end{abstract}

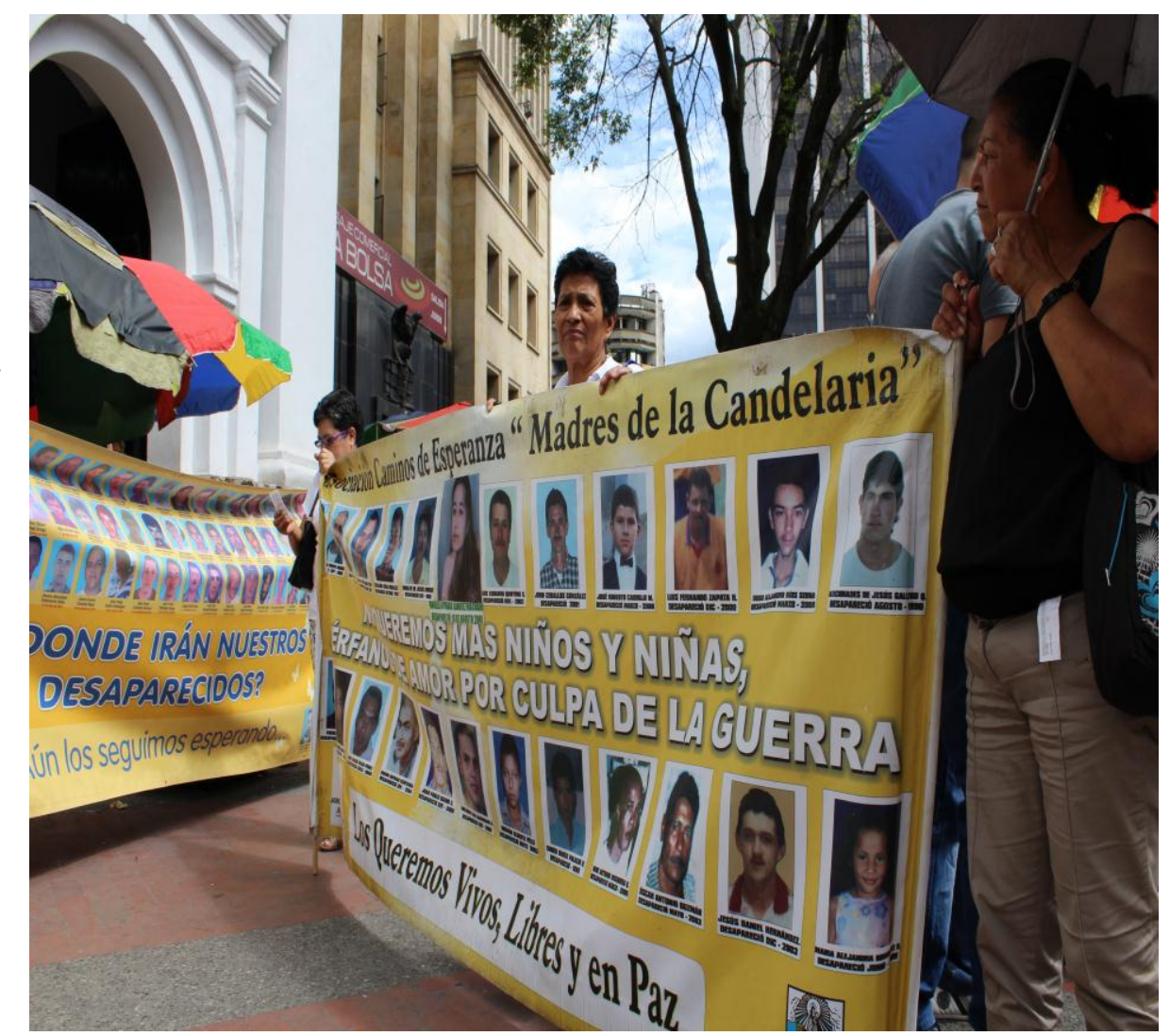

Una dimensión que cada vez cobra más importancia en la estrategia de comunicación $\mathrm{y}$ divulgación de los movimientos

sociales, es el uso de la Internet para gestionar y dar a conocer información y relacionarse con los simpatizantes. Como también lo expresa ${ }^{50}$, los movimientos ahora utilizan la Internet para coordinar actividades, dar noticias, recibir las opiniones de ciudadanos interesados. Del mismo modo, los foros de debate y las redes de información en la Internet se han convertido en herramientas organizativas esenciales para la construcción de acción colectiva.

Para el movimiento de "Madres de la Candelaria", las nuevas tecnologías de la información, han sido de gran ayuda, reduciendo costos en su campaña y haciendo más horizontal la relación entre el movimiento, los ciudadanos y los actores del poder político, tanto en el ámbito nacional e internacional como en el subnacional. De igual forma, las redes sociales han ayudado a 1 movimiento de Madres a conectarse con otros colectivos de derechos humanos, con medios de comunicación y legitimadores de la causa en todo el país.

De igual forma, la labor en relaciones públicas que ha realizado dicho movimiento a partir del liderazgo de Teresita Gaviria ha sido notable, estableciendo vínculos con los gobernantes locales y nacionales, la comunidad internacional y grupos de presión. De igual forma Teresita Gaviria ha establecido una comunicación directa con los líderes de grupos armados, construyendo una verdadera red de información y unidad de búsqueda de los desaparecidos del conflicto armado, convirtiéndose en un referente para los

\footnotetext{
${ }^{50}$ Castells, 2009, , Op., Cit.
} 
medios de comunicación, en momentos en que la agenda pública trata los temas de víctimas, desaparecidos y proceso de paz con los grupos guerrilleros y paramilitares.

$\mathrm{Al}$ respecto queremos resaltar lo que expresan Castells y Alain Touraine ${ }^{51}$, quienes advierten que lo indispensable no es tomar el poder, sino recrear la sociedad, y destacan el papel crucial de los medios de comunicación en la política contemporánea, afirmando que debido a los efectos de la crisis de los sistemas políticos tradicionales y del espectacular aumento de la penetración de los nuevos medios, la información política ha quedado capturada en el espacio de los medios de comunicación, los mismos que empíricamente usados por los colectivos de mujeres, las han catapultado en el mundo de la política, convirtiéndolas en fuertes agentes de incidencia que unidas alrededor de su catástrofe personal y familiar, posibilitan el cambio social.

Así pues, Castells al respecto es categórico al advertir la dependencia de estos grupos sociales hacia los medios de comunicación, ya que en las sociedades contemporáneas, la gente recibe la información y forma su opinión política esencialmente a través de estos. Por ello para actuar sobre las gentes, las opciones políticas en conflicto, encarnadas en partidos políticos, poderes gremiales y grupos de presión, utilizan los medios como vehículo fundamental de comunicación, influencia y persuasión; ya que son estos los que moldean la política, puesto que en todo momento un gobierno o un grupo social como los colectivos de mujeres que nos ocupan, dependen de la legitimidad y el reconocimiento ${ }^{52}$.

Sin embargo, y pese a los logros y avances cosechados gracias a sus esfuerzos comunicativos, también debemos destacar que esa carencia de medios y ausencia de profesionalización ha tenido, aunque en menor medida, consecuencias negativas que han mermado la capacidad comunicativa y de difusión de las acciones y reivindicaciones de ambas organizaciones. En este sentido, los escasos recursos existentes, ha menguado la capacidad de internacionalización de sus mensajes y estrategias comunicativas. Al carecer de medios económicos suficientes debido a su condición de mujeres de clase social humilde en su mayoría, la actualización de contenidos casi permanentes que requiere un espacio digital se torna en labor casi imposible, lo que ha provocado que las informaciones de sus webs de referencia se hayan quedado obsoletas y no recojan fielmente las numerosas actividades organizadas por ambas organizaciones, ni los avances que día a día van cosechando gracias a su trabajo. Asimismo, esta misma carencia de recursos provoca demoras en las contestaciones a periodistas, medios o activistas interesados en difundir sus actuaciones. Todo ello, ha mermado considerablemente su capacidad comunicativa, sobre todo en el ámbito internacional, ya que en el ámbito local, departamental e incluso nacional, ambas han conseguido tejer una red de contactos directos con medios y periodistas, estableciendo con ellos relaciones de complicidad basadas en una comunicación horizontal, cívica y democrática alimentando la solidaridad, el respeto y el diálogo ${ }^{53}$.

\footnotetext{
${ }^{51}$ Castells, Manuel, La Sociedad en Red, Madrid, Alianza Editorial, 1998

${ }^{52}$ Ibid, p. 404-406

${ }^{53}$ Cortina, Adela, Ética la razón cordial. Educar en la ciudadanía en el siglo XXI, España, 2009
} 


\section{Conclusiones}

Una vez desarrollado nuestro proceso de investigación, podemos concluir que movimientos conformados por mujeres analizados se han consolidado, con sus estrategias y campañas de comunicación, como agentes de influencia y persuasión que desafían las interpretaciones dominantes y se han convertido en referentes en la defensa de valores compartidos por el conjunto de una sociedad, la colombiana, pluralista, es decir, que cuenta con visiones y códigos morales diferentes, pero logra el entendimiento a través del diálogo y elevando a las personas como protagonistas ${ }^{54}$. Ese trabajo social y esa labor de contrapoder han incidido en todos los ámbitos de la política desde lo simbólico, porque es un sistema de narraciones que pretende mostrar y expresar los conflictos ante la sociedad: La iglesia de La Candelaria, La Iglesia de la Madre Laura, las camisetas blancas, la sororidad, las fotografías y los cantos.

Podemos afirmar que, una vez analizados los movimientos de sororidad de las mujeres de Medellín, focalizados en las dos organizaciones estudiadas, estos se han consolidado a lo largo de los años como interlocutores sociales aceptados y respetados tanto por medios de comunicación como por el conjunto de la sociedad, adquiriendo, además, el reconocimiento como actores políticos. De este modo, concluimos que la hipótesis inicial de la que partíamos, según la cual las mujeres habrían construido durante años de forma conscientemente los modelos y roles de género para dar significado a su activismo político, viendo su activismo político como respuesta a un patriarcado hegemónico que históricamente ha tratado de silenciarles es cierta, ya que, como hemos analizado, su lucha se ha focalizado en una concepción de género, donde han hecho frente a un sistema dominado por hombres en el que las mujeres eran inviabilizadas socialmente y sus acciones se reducían al ámbito doméstico.

Este movimiento de sororidad se ha consolidado en un actor político que incide directamente en el conflicto, que busca cambiar en todo momento las fuerzas y poderes existentes, y modificar la realidad del conflicto, también con una sensibilidad de género, tratando de cambiar los roles sexistas y reivindicando a las mujeres como parte esencial de la construcción de la Paz. Gracias a esta labor de años, hoy en el ámbito institucional los movimientos de mujeres tienen un papel preponderante, ya que inciden directamente en los espacios que regulan y canalizan los actores del conflicto, a través de la interacción y negociación con los bandos y actores del conflicto a partir de la legitimidad lograda por las estrategias de comunicación y la homogeneidad como grupo.

Comunicar y transmitir las exigencias, por parte del movimiento de mujeres supone debelar las demandas que de otro modo quedarían silenciadas. De igual forma ambos grupos logran en su interior generar identidad y solidaridad entre las mujeres, además de forjar seguidores de la causa en todo el país convenciendo a los participantes y a la opinión pública de los fuertes que pueden llegar a ser y de los cambios que se pueden dar en una sociedad tan golpeada por la violencia como la colombiana. Sin embargo, es importante resaltar que a pesar de sus similitudes, sus mensajes, reivindicaciones y el estilo formal de las relaciones públicas que desarrollan difiere: mientras las "Madres de la Candelaria"

${ }^{54}$ Idem. 
parten de una aplicación más concertada con los diferentes perpetradores de la violencia, apostando por un mensaje más conciliador, aunque no por ello menos reivindicativo; "Mujeres Caminando por la Verdad", pese a su clara apuesta por la Paz, inciden en una perspectiva que aboga más por la denuncia y la exigencia de Justicia, con un activismo directo y muy visible que les ha consolidado, como hemos analizado, como interlocutores respetados por medios de comunicación, autoridades y ciudadanía.

Debido a lo anterior, las "Madres de la Candelaria" y "Las Mujeres Caminando por la Verdad" han logrado en estos años de lucha transformaciones significativas en los sistemas de valores, opiniones, actitudes en la población colombiana y en especial en la ciudad de Medellín. De igual forma han ayudado a generar cambios en la estructura de representación política y la creación de nuevos espacios y mecanismos estables de negociación con autoridades, empujando el cambio de las políticas gubernamentales, obteniendo derechos individuales, civiles y sociales que impactan en ámbito público, convirtiéndose no sólo en actores políticos sino en defensoras de otra forma de ser madres y mujeres que crean nuevas oportunidades para la movilización.

Por último, destacar que, pese a los logros de sus estrategias comunicativas y los enormes avances cosechados gracias a su trabajo y esfuerzo, la carencia de medios económicos y recursos, así como la ausencia de profesionalización, han mermado claramente la capacidad de internacionalizar y proyectar más y mejor al conjunto de la sociedad la lucha y las reivindicaciones de ambas organizaciones. Pese al esfuerzo de sus integrantes y su encomiable labor por adaptarse a las nuevas exigencias comunicativas, el resultado, aunque positivo, ha sido insuficiente, precisamente por esa ausencia de poder adquisitivo y capital humano suficiente para responder a las exigencias que los nuevos medios y plataformas de comunicación requieren.

\section{Bibliografía}

Agudelo, Carlos, Nuevos actores sociales y relegitimación del Estado. Estado y construcción del movimiento social de las comunidades negras en Colombia, En Revista Análisis Político (Bogotá) n 43, Bogotá, mayo-agosto de 2001, p. 3-31

Alcañiz, Mercedes, Aportaciones de las mujeres al discurso y a la práctica de la paz en Revista Feminismo/s, En Revista Feminismos (Alicante) n. 9, Alicante, 2007. pp. 31-50

Amnistía Internacional, Déjenos en Paz: la población civil víctima del conflicto armado interno de Colombia, Madrid, EDAI, 2008

Amnistía Internacional, Eso es lo que nosotras exigimos. Qué se haga Justicia: Impunidad por actos de violencia sexual cometidos contra mujeres en el conflicto armado de Colombia, Madrid, EDAI, 2011

Amnistía Internacional, Colombia: restituir la tierra, asegurar la paz. Los derechos territoriales de las comunidades indígenas y afrodescendientes. Reino Unido. 2015. 
Amorós, Celia, Feminismo: Igualdad y Diferencia, México, PUEG- Programa Universitario de Estudios de Género, Universidad Nacional Autónoma de México. 1994, p.27

Antequera, José Dario, Contribuciones para la reivindicación social de un derecho a la memoria, En Revista el Otro Derecho (Bogotá) n. 37, Bogotá, 2007, pp. 65-96

Aricapa, Ricardo, Comuna 1, crónica de una guerra. De Orión a la Escombrera, Bogotá, Ediciones B, 2015.

Ariza, Gladys Rocio, Hacia la definición de la violencia en las relaciones de pareja como un problema de salud pública en Medellín a comienzos del siglo XXI, En: Revista del Centro de Estudios sobre la Mujer de la Universidad de Alicante, n 18, Alicante, pp. 67-92

Benítez, Lucia, La perspectiva de Género en Comunicación al desarrollo, En Comunicación y Desarrollo: Prácticas comunicativas y empoderamiento, Barcelona, Gedisa S.A., 2015

Castells, Manuel, La Sociedad en Red, Madrid, Alianza Editorial, 1998, pp.628

Castells, Manuel, Comunicación y poder, Madrid, Alianza Editorial, 2009

Cortina, Adela, Ética la razón cordial. Educar en la ciudadanía en el siglo XXI, España, 2009

Díaz, Flor, Estudio sobre la tolerancia social e institucional a la violencia basada en género en Colombia, Bogotá, UNIFEM, UNFPA, OIM Y MDGF, 2010

González, Eduardo y Varney, Howard, En busca de la Verdad. Elementos para la creación de una comisión de la verdad eficaz, Brasilia, González y Varney, 2013

Guisao, Paula, De mujeres, luchas y memorias en el conflicto colombiano, Buenos Aires, En Memorias del IV Seminario Internacional de la Memoria, 2011

Huntington, Samuel, La tercera Ola: La democratización a finales del Siglo XX, España, 1994.

Hernández, Roberto; Fernández, Carlos y Baptista, Pilar, Metodología de Investigación, México, McGraw Hill, 2010

Hernández, Colombia y Yepes, Fanny Lucia, Haciendo visible lo invisible. Violencia de género y entre generaciones en una comunidad indígena colombiana, En Revista Investigación y Educación en Enfermería, Universidad de Antioquia, Vol 28, n 3 (Medellín), pp. 444-453

Hierro, Graciela, Las mujeres asesinadas en Ciudad Juárez, En: Violencia Sexista. Algunas claves para la compresión del feminicidio en Ciudad Juárez, México, Programa Universitario de Estudios de Género, Universidad Nacional Autónoma de México, 2004, pp. 126-127

Jensen, Klaus y Jankowski, Nicholas, Metodologías cualitativas de investigación en comunicación de masas, Barcelona, Boch Casa Editorial S.A., 1993

Lagarde, Marcela, El feminismo en mi vida: hitos, claves y topias, México, Inmujeres, 2012 
Lamus, Doris, La construcción de movimientos Latinoamericanos de mujeres/feministas: aportes a la discusión teórica y a la investigación empírica, desde la experiencia en Colombia, En Revista Reflexión Política, n.18, Bucaramanga, 2007, pp.119-132

Lamus, Doris, De la subversión a la inclusión: movimientos de mujeres de la segunda ola en Colombia 1975-2005. Instituto Colombiano de Antropología e Historia. Bogotá (Colombia). 2010. p. 111

Leiras, Marcelo, La incidencia de las organizaciones de la sociedad civil en las políticas públicas. Definiciones, explicaciones y evaluaciones de la literatura especializada local e internacional, En: La incidencia política de la sociedad civil, Buenos Aires, Ed Siglo XXI, 2007. Pp. 17-65

Martinez, Juliana, Las madres de la Candelaria- Línea Fundadora, En: Revista Anuario de Hojas Warmi, Universitat de Barcelona, n. 15, Barcelona, 2010, pp. 15

Morlino, Leonardo y Sartoni, Giovanni, La comparación en las ciencias sociales, Madrid, Alianza Editora, 1999

Ortiz, William, Los paraestados en Colombia, Tesis Doctoral, Facultad de Sociología y Ciencias Políticas, Universidad de Granada (España), 2006

Ramírez, Patricia, El movimiento de mujeres frente al conflicto armado en Colombia y la construcción de la paz 1998-2008, En Revista Foro (Colombia) n 67, Colombia, 2009, pp. 31-43

Rovira, Guiomar, Movimientos sociales y comunicación: la red como paradigma, En Revista Análisis (Bogotá) n.45, Bogotá, 2012, pp. 92-96

Rozema, Ralph, Paramilitares y Violencia Urbana en Medellín, Colombia, En Foro Internacional, Vol. XLVII, n. 3 Julio- Septiembre de 2007, México, pp. 535

Segato, Rita Laura. Territorio, soberanía y crimenes de segundo Estado: la escritura en el cuerpo de las mujeres asesinadas en Ciudad Juárez. Brasilia. Departamento de Antropología Universidad de Brasilia. 2004, p.11.

Solís, Juan Mario, Dos visione, dos historias de la Plaza de Mayo. Estrategias de Abuelas y Madres para la articulación de políticas públicas de la memoria en la Argentina, Seminario de Investigación, Salamanca, Instituto de Iberoamérica y Portugal, 2010.

Truño, María, No solo víctimas: mujeres en el lugar social de víctima y relaciones de género, En: Revista el Otro Derecho (Bogotá) n. 36, Bogotá, 2007, pp. 129-147

On- Line

Bernal, Ana Teresa, Memorias del Foro Iniciativas de Paz: una lógica de vida, Mayo 24 de 2005, En: http://documentos.pas.org.co/Memorias Foro\%20Iniciativas\%20de\%20Paz\%202005.pdf

Martí i Piug, Salvador, "Los movimientos sociales en un mundo Globalizado: ¿alguna novedad?”, 2004, En: https://campus.usal.es/ dpublico/areacp/materiales/Losmovimientossociales.pdf 
Noreña, Ana Lucia; Alcaraz-Moreno, Noemi; Rojas, Juan Guillermo y Robellado-Malpica, Dinora, Aplicabilidad de los criterios de rigor y éticos en la investigación cualitativa, 2012, En: file:///C:/Users/nebotero/Downloads/Dialnet-

AplicabilidadDeLosCriteriosDeRigorYEticosEnLaInves-4322420.pdf

RCN Radio, Mujeres caminando por la verdad en Medellín fue nominada a premio, 3 de Septiembre de 2015, En: http://www.rcnradio.com/locales/mujeres-caminando-por-la-verdad-demedellin-fue-nominada-al-premio-nacional-a-la-defensa-de-los-derechos-humanos/ (Consultado el 2 de junio de 2016)

Ospina, Gustavo, Las mujeres que destaparon la verdad sobre La Escombrera, Periódico El Colombiano, En: http://www.elcolombiano.com/antioquia/excavacion-a-la-escombrera-una-luchade-un-colectivo-de-mujeres-IE2503864

Touraine, Alain, ¿Podemos vivir juntos?,Bogotá,Fondo de Cultura Económica, 2000, p.99

1 Martí i Piug, Salvador, "Los movimientos sociales en un mundo Globalizado: ¿alguna novedad?”, 2004, En: https://campus.usal.es/ dpublico/areacp/materiales/Losmovimientossociales.pdf 